\title{
High levels of endothelial progenitor cells and circulating endothelial cells in patients with Behçet's disease and their relationship to disease activity* $^{*}$
}

\author{
Deniz Aksu Arica ${ }^{1}$, Burak Akşan ${ }^{1}$, Asim Örem², Buket Akcan Altinkaynak ${ }^{2}$, Savaş Yayli1 ${ }^{1}$, Mehmet Sönmez ${ }^{3}$
}

DOI: http:/ / dx.doi.org/10.1590/abd1806-4841.20198169

\begin{abstract}
BACKGROUND: Behçet's disease is a multisystemic vasculitis, associated with vascular endothelial dysfunction. Currently, the prognosis is unpredictable, because there is still no valid laboratory marker indicating the disease activity in Behçet's disease. Endothelial progenitor cells and circulating endothelial cells are newly introduced hematological markers which are presumed to take part in the pathogenesis of vasculitis.

Овјестіvеs: To evaluate the levels of endothelial progenitor cells and subtypes and circulating endothelial cells in patients with Behçet's disease and to describe their relationship with the disease activity.

Methods: A total of 45 patients with Behçet's disease and 28 healthy controls were included in the study. Endothelial progenitor cells (CD34+CD133+KDR+ as early endothelial progenitor cells and CD34+KDR+ as late endothelial progenitor cells), and circulating endothelial cells (CD34+CD133+) were measured by flow cytometry.

REsults: The mean plasma level of endothelial progenitor cells and circulating endothelial cells, vascular endothelial growth factor, matrix metalloproteinase-9, C-reactive protein, and erythrocyte sedimentation rate were significantly higher in patients with Behçet's disease. All of these parameters except circulating endothelial cells were also found to be higher in patients with active disease than in patients with inactive disease. Early endothelial progenitor cells showed significant correlations with C-reactive protein and circulating endothelial cells.

StUdy Limitations: The cross-sectional nature of the study and patient characteristics such as being under treatment, which can affect endothelial progenitor cells numbers.

CONCLUSION: The increase in endothelial progenitor cells may play an essential role in the repair of endothelial injury in Behçet's disease, especially in the active period of the disease. Thus, endothelial progenitor cells can indicate the disease activity. In addition, endothelial progenitor cells and circulating endothelial cells can be used as endothelial repair and injury markers for Behçet's disease, respectively.
\end{abstract}

Keywords: Behçet's disease; Endothelial cells; Matrix Metalloproteinase-9; Vascular endothelial growth factor A

\section{INTRODUCTION}

Behçet's disease (BD) is a chronic multisystemic disorder resulting from vasculitis and associated with vascular endothelial dysfunction. It is now classified as a mixed pattern disease exhibiting the characteristics of both autoinflammatory disorders and autoimmune diseases. Endothelial damage, activation of coagulation, and thrombosis are shown to be important in the pathogenesis. ${ }^{1-3}$

Endothelial progenitor cells (EPCs) are bone marrow-derived heterogeneous immature cells which appear in neovascular- ization and vascular homeostasis. ${ }^{4,5}$ In response to vascular inflammation, injury, or tissue ischemia, they migrate to the peripheral circulation and convert into mature endothelial cells to reestablish vascular integrity and blood supply. ${ }^{6-9}$ EPCs express CD34 and CD133 as hematopoietic progenitor markers and KDR (kinase insert domain receptor, called vascular endothelial growth factor receptor-2, VEGFR2) as an endothelial-lineage marker during the differentiation stage. At the end of this stage, CD133 expression vanishes

\footnotetext{
Received 07 February 2018

Accepted 07 June 2018.

* Work conducted at the Faculty of Medicine, Karadeniz Technical University, Trabzon, Turkey.

Financial support: This study was supported by the Scientific Research Unit of Karadeniz Technical University, under project number 1213.

Conflict of interest: None.

Department of Dermatology and Venereology, Faculty of Medicine, Karadeniz Technical University, Trabzon, Turkey.

Department of Biochemistry, Faculty of Medicine, Karadeniz Technical University, Trabzon, Turkey.

Department of Hematology, Faculty of Medicine, Karadeniz Technical University, Trabzon, Turkey. 
and the cells are called late or mature EPCs and have little or no vasculogenic and repair capability. ${ }^{10}$ Besides, circulating endothelial cells (CECs), $\mathrm{CD} 34^{+} \mathrm{CD} 133^{+}$cells, are cells that have detached from the vessel wall endothelium due to injury or disease. Unlike EPCs, CECs lack the ability to become endothelial cells again. They may be a relevant biomarker of vascular disease. Pro-angiogenic growth factors like vascular endothelial growth factor (VEGF) and matrix metalloproteinase-9 (MMP-9), which may become apparent with endothelial damage, play a crucial role in inducing the mobility of EPCs from bone marrow into the peripheral blood. ${ }^{11,12}$

In the currently available human data, there are limited studies that have investigated the association between EPC levels and disease activity in $\mathrm{BD}$, and the results of such studies are inconsistent in respect to EPC levels and the relationship to disease activity, mainly due to the different protocols used for EPC quantitation. ${ }^{9,13,14}$ Also, correlation of EPCs with well-known inflammatory markers such as C-reactive protein (CRP), erythrocyte sedimentation rate (ESR), VEGF, and MMP-9 levels in patients with BD have not been studied to date on a large scale.

This study aims to evaluate the levels of EPCs, CECs, VEGF, and MMP-9 in patients with Behçet's disease and to investigate their relationship to disease activity.

\section{METHODS}

\section{Study design and groups}

A total of 45 patients with BD diagnosed according to the criteria of the International Study Group for Behçet's Disease, and 28 healthy control volunteers were included in this case-control cross-sectional study. ${ }^{15}$ The Hospital Ethics Committee approved the study, and written informed consent was obtained from all subjects. All procedures complied with Good Clinical Practice standards, the ethical standards of the Responsible Committee on $\mathrm{Hu}$ man Experimentation, and the Declaration of Helsinki.

Exclusion criteria for the control group were use of any medication, signs and symptoms of any clinical infection or systemic disease, and any invasive procedure during the month before blood collection. In the patient group, individuals with a diagnosis of any chronic illness other than BD or symptoms or history of coronary artery disease, malignancy, and pregnancy were excluded.

Patients with at least one mucocutaneous lesion or active organ involvement were considered to have "active disease" $(n=32)$. Patients who did not have any mucocutaneous lesions or systemic complaints at the time of blood collection were defined as having "inactive disease" ( $n=13)$.

\section{Blood sample collection and analysis}

Peripheral blood samples were drawn into tubes containing ethylenediaminetetraacetic acid (EDTA) as an anticoagulant and gel tubes without anticoagulant in the morning after overnight fasting. Samples were centrifuged immediately for 15 minutes at $3000 \mathrm{rpm}$ at $4^{\circ} \mathrm{C}$; then, the plasma and serum were stored at $-80^{\circ} \mathrm{C}$ until being assayed. Blood samples with the anticoagulant were used the same day for analysis of EPCs and CECs.

The number of EPCs was determined by flow cytometry (FACS Calibur, Becton Dickinson); briefly, $100 \mu \mathrm{L}$ whole blood incubated with fluorochrome-labeled antibodies to CD133 mAB-PE
(Miltenyi Biotec), CD34 mAB-PC (Beckman Coulter), and VEGFR2/ KDR-FITC (R\&D System) antibodies at room temperature for 10 minutes. After red cell lysis, the samples were washed and incubated with FITC and PE at room temperature for 15 minutes. For analysis, first CD34 or CD133 positive cells were gated, identified as a distinct cell population with high expression of the antigens mentioned above and low side scatter, and then these cells were assayed for KDR expression in the mononuclear cell fraction. Cells that were $\mathrm{CD} 34^{+} \mathrm{KDR}^{+}$(late EPCs) and $\mathrm{CD} 34^{+} \mathrm{CD} 133^{+} \mathrm{KDR}^{+}$(early EPCs) were considered EPCs. ${ }^{7} \mathrm{CD} 34^{+} \mathrm{CD} 133^{+}$cells were considered CECs. For all the analyses, $5 \times 10^{5}$ events were collected and scored using a FACS Calibur analyzer (Becton Dickinson). The data were processed using the Macintosh CELL Quest software package (Becton Dickinson), and the cell count was expressed per one million cytometric events.

Serum VEGF and MMP-9 levels were measured using commercial ELISA kits (R\&D System Quantikine Human VEGF and MMP-9 Immunoassay Minneapolis, MN, USA) according to the manufacturer's standard protocols. The appropriate recombinant human VEGF was used for calibration. Sensitivity of the present assay for VEGF was $9 \mathrm{pg} / \mathrm{mL}$ and for MMP-9 was $0.156 \mathrm{ng} / \mathrm{mL}$.

CRP level was determined by immunoturbidimetric assay (Beckman Coulter AU5800, Mishima, Japan). Mean ESR was measured with the capillary kinetic photometric assay (Alifax Test1 THL, Polverara, Italy). CRP and ESR levels were measured after the analyzing test systems were run on daily quality control reference reagents at the Clinical Biochemistry Laboratory of Medical Faculty, Karadeniz Technical University.

\section{Statistical analysis}

The data are presented as the mean \pm standard deviation for normally distributed variables and as median values (interquartile range for $25-75 \%$ ) for non-normally distributed variables. The normal distribution was checked using the Kolmogorov-Smirnov test for continuous variables. Comparison between two groups was performed using Student's t-test for continuous normally distributed data and Mann-Whitney test for non-normal variables. Chi-square test was used for categorical variables. The variables used to assess the correlation were not linear, so Spearman rank correlation test was performed to investigate associations between the non-normally distributed variables. The sensitivity, specificity, area under the curve (AUC), and receiver operating characteristic (ROC) curve for EPCs and EPC subtypes, CECs, CRP, and ESR levels in the BD group were assessed using ROC curve analysis. All the statistical analyses were performed with SPSS for Windows ${ }^{\circledR}$ Version 15.0 (SPSS Inc., Chicago, IL, USA). P values less than 0.05 were accepted as statistically significant.

\section{RESULTS}

A total of 45 patients with BD (22 females and 23 males, 36.7 \pm 10.3 years) and 28 age- and sex-matched healthy individuals as the control group were included in the study. BD patients had mean disease duration of $5.49 \pm 5.04$ years (median 5, range $0-22$ years). Table 1 shows the cumulative frequencies of clinical involvement of patients with BD. They were characterized by predominantly mucocutaneous involvement, since all had a history of recurrent oral aph- 
thous lesions, and most patients had a history of genital ulceration $(86.7 \%)$, erythema nodosum $(62.2 \%)$, and typical papulopustular eruptions $(64.4 \%)$. Thirty-two out of 45 patients had a minimum of one active mucocutaneous lesion or organ involvement, and they were defined as having active disease. Thirteen out of 45 patients had no any active complaints when they were enrolled in the study. A total of 32 patients were on chronic colchicine therapy, of whom 16 were receiving a minimum of one extra immunosuppressive drug (azathioprine, corticosteroid, or cyclosporine).

The mean plasma level of EPCs (CD34+CD133+KDR+ as early EPCs and CD34+KDR+ as late EPCs), CECs (CD34+CD133+), VEGF, MMP-9, CRP, and ESR were significantly higher in patients with Behçet's disease than in healthy controls (Table 2). All of these variables except CECs and ESR were also higher in patients with active disease, compared to those with inactive disease.

Mean levels of late EPCs (CD34+KDR+) (3.88 \pm 1.64$)$ and early EPCs (CD34+CD133+KDR+) $(3.0 \pm 1.10)$ in patients with vascular involvement were slightly higher than in the other patients

TABLE 1: Cumulative frequencies of clinical involvement in BD during the disease course

\begin{tabular}{lc} 
Manifestation & $\mathbf{N}^{\circ}$. of patients: $\mathbf{4 5}(\mathbf{\%})$ \\
\hline Oral Aphtha & $45(100)$ \\
Genital Ulcer & $39(86.7)$ \\
Ocular Involvement & $25(55.6)$ \\
Erythema Nodosum & $28(62.2)$ \\
Papulopustular Eruption & $29(64.4)$ \\
Vascular Involvement & $9(20)$ \\
Pathergy & $9(20)$ \\
Articular Involvement & $3(6.6)$ \\
Neurologic Involvement & $1(2.2)$ \\
Gastrointestinal Involvement & $1(2.2)$ \\
Epididymitis & $1(2.2)$ \\
\hline
\end{tabular}

( $3.32 \pm 1.90$ and $2.84 \pm 1.79$ respectively). However, the difference between the two groups was not statistically significant $(p>0.05)$.

Levels of early EPCs correlated with CRP $(r=0.33, p=$ 0.028 ) and CECs ( $r=0.41, p=0.005)$ (Figures 1 and 2). Early EPCs also correlated directly with late EPCs $(r=0.83, p=0.0001)$. The duration of $\mathrm{BD}$ did not correlate with levels of EPCs.

Figures $3 \mathrm{~A}$ and $\mathrm{B}$ show the AUC, sensitivity, and specificity obtained by ROC curve analysis of EPCs, CECs, CRP, and ESR levels in patients with $\mathrm{BD}$ and controls, and active and inactive patients with $\mathrm{BD}$, respectively. All of these variables were significant markers for BD. When compared to CRP and ESR as classical inflammatory markers, EPCs and CECs were found to be weaker (Figure 3A). As for disease activity, all the variables except CECs showed similar marker effects (Figure 3B).

\section{DISCUSSION}

The main goal of this study was to define the levels of EPCs and CECs in patients with Behçet's disease and their relationship to disease activity. The study demonstrated that the number of EPCs $\left(\mathrm{CD} 34^{+} \mathrm{CD} 133^{+} \mathrm{KDR}^{+}\right.$as early $\mathrm{EPCs}$ and $\mathrm{CD} 34^{+} \mathrm{KDR}^{+}$as late $\left.\mathrm{EPCs}\right)$ and CECs (CD34+CD133+) were significantly increased in BD in comparison with healthy controls. In addition, the number of EPCs in patients within the active period of the disease was significantly increased compared to patients with inactive disease.

Fadini et al. evaluated EPC levels in BD and associated BD with progressive EPC decline. ${ }^{9}$ They reported that patients with BD had significantly lower levels of EPCs (CD34+KDR+ and $\mathrm{CD} 34+\mathrm{CD} 133+\mathrm{KDR}+)$ than controls. However, our study showed significantly elevated levels of EPCs in patients with BD when compared to controls. This group also observed that some patients with higher disease activity had higher EPC levels, similar to our current findings, and concluded that EPC mobilization might occur during bursts of vascular inflammation. They concluded that while acute inflammation increases EPCs, over the long term a chronic inflammatory state may be accompanied by progressive EPC reduction. This hypothesis is consistent with data on other chronic diseases.

TABLE 2: Baseline demographic characteristics and laboratory variables in the study groups

\begin{tabular}{|c|c|c|c|c|c|c|}
\hline \multirow[b]{2}{*}{ Variables } & \multirow[b]{2}{*}{ Controls $(n=28)$} & \multirow[b]{2}{*}{ BD $(n=45)$} & \multirow[b]{2}{*}{$\mathbf{P}$} & \multicolumn{2}{|l|}{ Groups } & \multirow[b]{2}{*}{$\mathrm{p}$} \\
\hline & & & & $\begin{array}{l}\text { Patients with inactive } \\
\text { disease }(n=13)\end{array}$ & $\begin{array}{l}\text { Patients with active } \\
\text { disease }(n=32)\end{array}$ & \\
\hline Age (Years) & $35.7 \pm 7.51$ & $36.7 \pm 10.3$ & 0.661 & $35.9 \pm 9.22$ & $37.0 \pm 10.8$ & 0.761 \\
\hline CECs & $7.50(3.25-18.25)$ & $18.0(8.50-23.0)$ & 0.005 & $19.0(9.50-29.0)$ & $18.0(7.25-22.5)$ & 0.531 \\
\hline (CD34+CD133+) & $11.0 \pm 9.16$ & $20.4 \pm 20.4$ & & $19.0 \pm 11.3$ & $20.7 \pm 23.2$ & \\
\hline $\begin{array}{l}\text { Early EPCs } \\
\text { (CD34+CD133+KDR+) }\end{array}$ & $\begin{array}{c}2.0(0.00-2.0) \\
1.46 \pm 1.26\end{array}$ & $\begin{array}{c}3.0(1.50-4.0) \\
2.87 \pm 1.67\end{array}$ & 0.001 & $\begin{array}{l}2.0(1.0-2.5) \\
2.0 \pm 1.15\end{array}$ & $3.0(2.0-4.0)^{\mathrm{a}}$ & 0.021 \\
\hline Late EPCs & $1.68 \pm 1.33$ & $2.84 \pm 1.68$ & 0.0001 & $2.46 \pm 1.61$ & $3.22 \pm 1.74$ & 0.025 \\
\hline (CD34+KDR+) & & & & & $3.81 \pm 1.82^{\mathrm{a}}$ & \\
\hline MMP9 (ng/mL) & $351 \pm 194$ & $624 \pm 277$ & 0.0001 & $494 \pm 235^{\mathrm{b}}$ & $676 \pm 279^{a}$ & 0.045 \\
\hline VEGF (pg/mL) & $215(122-342)$ & 335 (222-527) & 0.020 & $218(128-439)$ & $345(239-546)^{c}$ & 0.043 \\
\hline CRP (mg/dL) & $0.085(0.043-0.150)$ & $0.450(0.330-0.830)$ & 0.0001 & $0.330(0.330-0.455)^{a}$ & $0.640(0.330-0.900)^{\mathrm{a}}$ & 0.029 \\
\hline ESR (mm/hour) & $6.75 \pm 3.62$ & $34.1 \pm 22.4$ & 0.0001 & $28.8 \pm 15.6^{\mathrm{a}}$ & $35.9 \pm 24.2^{\mathrm{a}}$ & 0.395 \\
\hline
\end{tabular}

Data were expressed as: median (inter quartile range for (25-75\%) for non-normal distribution according to Mann-Whitney $\mathrm{U}$ test and mean \pm SD for normal distribution according to Student's t-test. ${ }^{a} \mathrm{p}=0.0001$ compared to controls; ${ }^{b} \mathrm{p}=0.047$ compared to controls; ${ }^{c} \mathrm{p}=0.004$ compared to controls. 
For instance, while unstable angina pectoris is characterized by increased EPC levels, chronic ischemic heart disease evolves with progressively reduced EPCs. ${ }^{16,17}$ On this point, they also reported that disease chronicity was the primary adverse modulator of EPC levels. This was confirmed by the multivariate analysis showing BD duration as the only independent variable associated with EPC count. However, our study did not find any association between
EPCs and disease duration, which may be due to the relatively shorter disease duration in our patients.

In another study, Bozkirli et al. reported no difference in EPCs (CD146, CD31, and CD34) levels between BD patients with $\mathrm{BD}$ and healthy controls. ${ }^{13}$ However in vascular BD patients they observed an increased EPC count, although not statistically significant. They were also unable to show any correlation between EPC
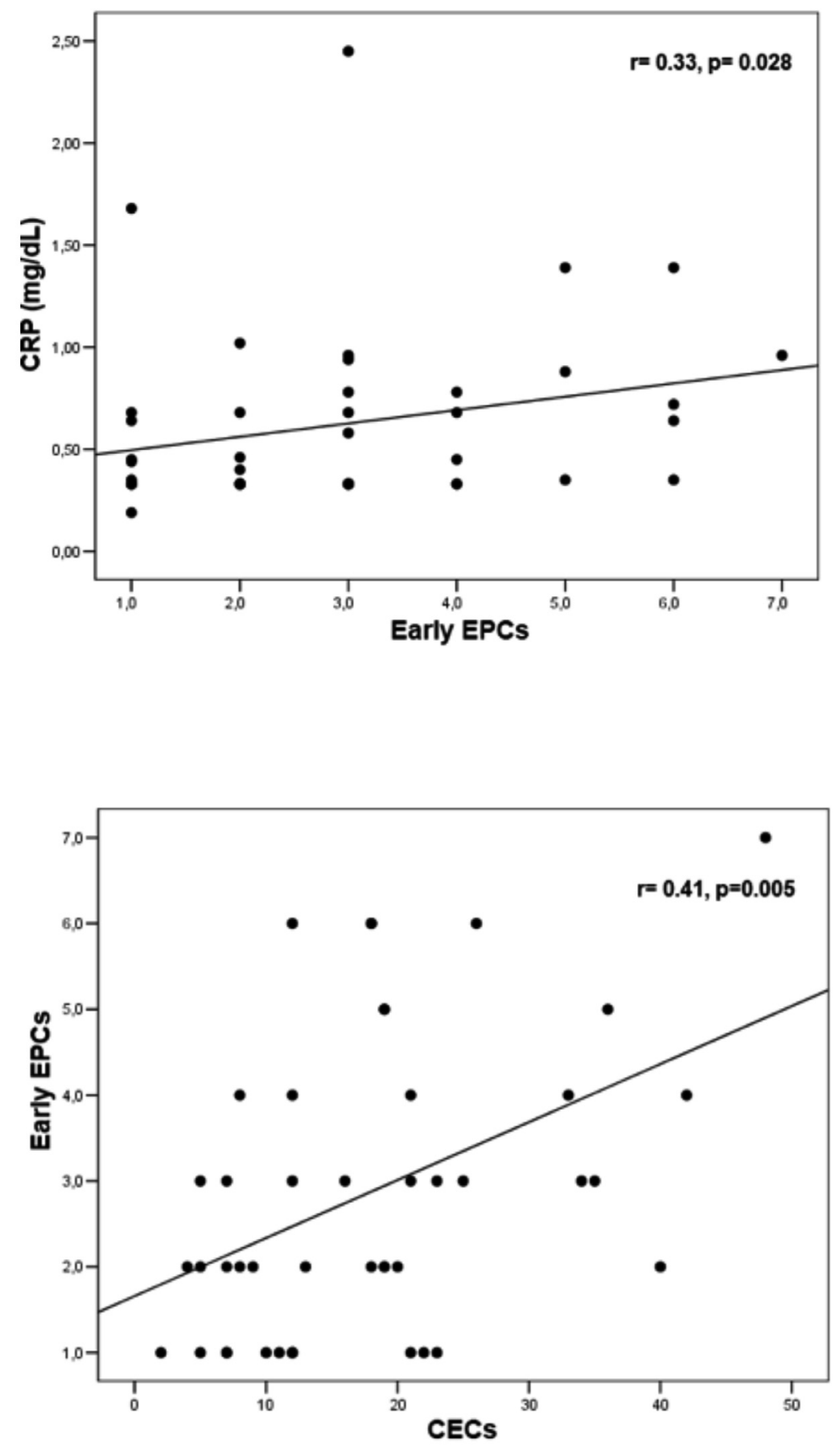

Figure 1: Linear correlations between early EPCs and $\mathrm{CRP}$ in $\mathrm{BD}$ patients
Figure 2: Linear correlations between early EPCs and CECs in BD patients 


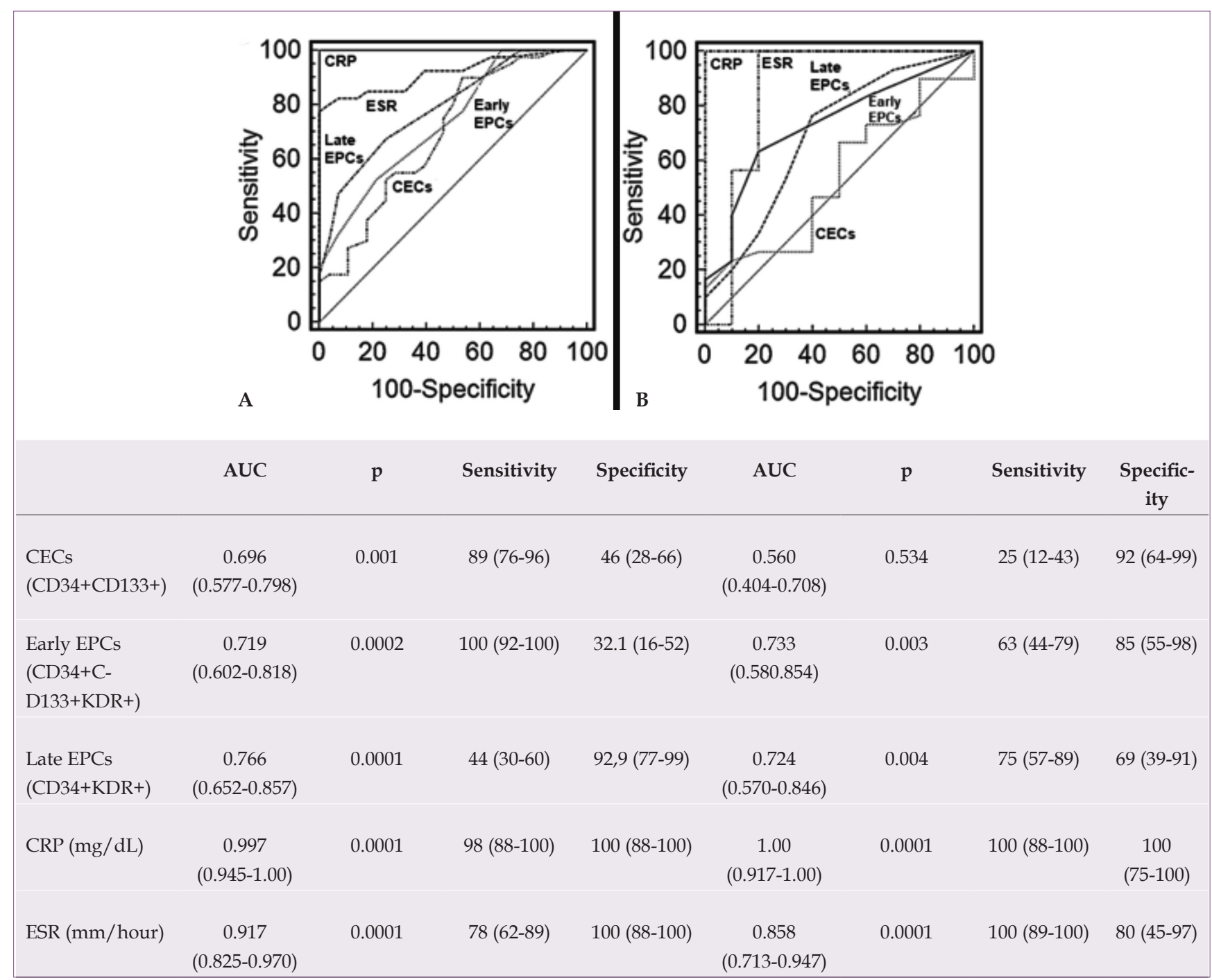

FIGURE 3: ROC curve analysis of variables in all BD patients and controls (A) and active and inactive patients with BD (B), and AUC, $p$ values, sensitivity, and specificity. $95 \%$ confidence intervals are shown in parentheses $(95 \% \mathrm{CI})$

count and acute phase CRP and ESR and disease duration.

Keskek et al. recently showed that EPC (CD146+ / CD31+/

CD45-/CD34+) levels in patients with Takayasu arteritis (TA) $(n=12)$ were approximately twice as high as those in BD patients $(\mathrm{n}=11) .{ }^{18}$ However, the difference in EPC levels between BD patients and controls was not statistically significant. The EPC evaluation criteria in that study differed from ours, and the sample was also very small, which could explain the different results. TA is a severe, progressive vasculitis with continuous inflammation in which endothelial injury and repair occur simultaneously. The elevated EPC levels in TA may be related to specific factors concerning the diverse histopathology between AT and DB.

Contradictory results for EPCs have also been reported in other autoimmune diseases such as systemic lupus erythematosus (SLE) and rheumatoid arthritis (RA). Some studies have proposed lower EPC levels in both SLE and RA, while others have reported higher levels or no difference. ${ }^{19-25}$ Lack of standardized procedures for quantitation of EPCs and different characteristics of study groups like disease activity/severity are probably the main reasons for inconsistencies in the study results.

CECs $\left(\mathrm{CD} 34^{+} \mathrm{CD} 133^{+}\right)$are cells that have detached from the vessel wall endothelium due to injury and/or disease and lack the ability to become endothelial cells again. They may be a relevant indicator of endothelial damage. Camion-Jau L et al. showed the relationships between CECs in BD and cerebral thrombophlebitis. ${ }^{26}$ Kutlay et al. found that the number of CECs was increased significantly in Behçet's vasculitis when compared to healthy controls. They also showed that CEC levels were significantly higher in patients with active disease compared to those with inactive disease. ${ }^{14}$ With regard to isolation of CECs, Kutlay et al. used the indirect cell separation technique, while others used flow cytometry. The mean plasma level of CECs (CD34+CD133+) in the present study was significantly higher in $\mathrm{BD}$ patients than in controls, but we found no correlation between CEC levels and disease activity (Table 2). The cells defined as CECs by Kutlay et al. were assessed generically and were likely to contain both EPCs and CECs. In our understanding, 
CECs do not display disease activity in Behçet's disease.

ROC curve analysis was performed to demonstrate the utility of EPCs and CECs as disease activity markers in BD (Figure 3). All the independent variables were found to be significant markers for BD. However, when compared to CRP and ESR as classical indicators of inflammation, EPCs and CECs were found to be weaker markers (Figure 3A). With regard to disease activity, similar findings were observed, except for CECs (Figure 3B). These results suggest that disease activity may result in elevated EPCs levels, which can be used as disease activity marker for BD, and the inflammatory endothelial cells released from lesions of ongoing/recent inflammation may result in increased CECs levels, which can be used as a marker of endothelial damage in BD. According to ROC curve analysis of CRP and ESR, these variables can be still useful inflammatory biomarkers for diagnosing and monitoring $\mathrm{BD}$ and disease activity (Figure 3). We have reported similar results in previous studies. ${ }^{27-29}$

Mean plasma VEGF and MMP-9 were significantly higher in BD patients than in controls (Table 2). VEGF and MMP-9 levels were also higher in patients with active disease than in those with inactive disease. Pro-angiogenic factors such as VEGF can mobilize EPCs and may enhance their recruitment to the site of endothelial injury. Previous studies have reported higher VEGF levels in many autoimmune and infectious inflammatory diseases. ${ }^{30-32}$ There are limited numbers of studies that have measured VEGF levels in BD. Most found that plasma VEGF levels were higher in BD patients than in controls, as in our study. ${ }^{33-37}$ Only one study showed a significant association between VEGF level and disease activity in BD patients. ${ }^{33}$ VEGF was presumed to be a marker of endothelial dysfunction. Our study also found significantly elevated VEGF levels in patients with active BD. We conclude that VEGF levels can be a helpful biomarker for disease activity in BD.

Matrix metalloproteinases are a family of calcium- or zinc-dependent endopeptidases that degrade the components of the extracellular matrix, playing a significant role in the release of EPCs from bone marrow. MMP-9 is a gelatinase, and it can degrade the subendothelial basement membrane by its elastinolytic activity. ${ }^{38}$ It can thus play a crucial role in the pathogenesis of vasculitis especially characterized by aneurysm formation, as in BD. ${ }^{39-41}$ Increased MMP-9 levels have been demonstrated in Kawasaki disease, temporal arteritis, and Takayasu's arteritis and were also found to correlated with disease activity score in TA..$^{40-42}$ Few studies have evaluated serum MMP-9 levels in BD. ${ }^{39,43-45}$ Most of them showed higher MMP-9 levels in BD patients than in controls, similar to our findings. MMP-9 showed a strong association with vascular BD, particularly with aneurysmal involvement, suggesting its pathogenetic role in vascular BD complicated by aneurysmal formation. ${ }^{39}$ MMP-9 levels were also found to be increased in BD patients with visceral and ocular involvement. ${ }^{44,45}$

The above-mentioned findings suggest that systemic inflammation (increased CRP) and vascular endothelial damage (increased CECs) in $\mathrm{BD}$, especially in the active period of the disease, result in increased VEGF release. The latter plays a vital role in inducing EPC levels in the bone marrow. Simultaneously, increased MMP-9 levels participate in the release of EPCs from the bone marrow into the peripheral circulation with the aim of reestablishing vascular integrity.

The study has some limitations, such as the cross-sectional design. Patients were on medication, which has the potential to decrease EPC levels in the peripheral blood. One solution to offset these undesirable effects would be to increase the number of study participants. Our study had the largest patient sample of all studies published to date on this subject.

\section{CONCLUSION}

We conclude that increased EPC levels can play an essential role in the repair of endothelial injury in patients with Behçet's disease, especially during the active period. EPCs and CECs can also be used as markers of endothelial repair and injury in $\mathrm{BD}$, respectively. The findings highlight the role of EPCs in BD, and future studies focusing on their function in the development of the disease can increase our knowledge of Behçet's disease pathogenesis.

\section{ACKNOWLEDGEMENTS}

The authors wish to thank Dr. Bekir Bulut (Karadeniz Technical University, Faculty of Medicine, Department of Public Health, Trabzon, Turkey) and Dr. Serap Ozer Yaman (Karadeniz Technical University, Faculty of Medicine, Department of Biochemistry, Trabzon, Turkey) for statistical editing and Prof. Dr. Sevgi Bahadir (Karadeniz Technical University, Faculty of Medicine, Department of Dermatology, Trabzon, Turkey) for dedicated support. The study was supported by the Scientific Research Unit of Karadeniz Technical University, under project number 1213.

\section{REFERENCES}

1. Yazici H, Fresko I, Yurdakul S. Behçet's syndrome: disease manifestations, management, and advances in treatment. Nat Clin Pract Rheumatol. 2007;3:148-55.

2. Gul A. Behçet's disease as an autoinflammatory disorder. Curr Drug Targets Inflamm Allergy. 2005;4:81-3.

3. Galeazzi M, Gasbarrini G, Ghirardello A, Grandemange S, Hoffman HM, Manna R, et al. Autoinflammatory syndromes. Clin Exp Rheumatol. 2006;24(Suppl 40):S79-85.

4. Fadini GP, Coracina A, Baesso I, Agostini C, Tiengo A, Avogaro A, et al. Peripheral blood CD34+KDR + endothelial progenitor cells are determinants of subclinical atherosclerosis in a middle-aged general population. Stroke. 2006;37:2277-82.

5. Urbich C, Dimmeler S. Endothelial progenitor cells: characterization and role in vascular biology. Circ Res. 2004;95:343-53.

6. Takahashi T, Kalka C, Masuda H, Chen D, Silver M, Kearney M, Magner M, et al. Ischemia- and cytokine-induced mobilization of bone marrow-derived endothelial progenitor cells for neovascularization. Nat Med. 1999;5:434-8.

7. George J, Goldstein E, Abashidze S, Deutsch V, Shmilovich H, Finkelstein A,

et al. Circulating endothelial progenitor cells in patients with unstable angina: association with systemic inflammation. Eur Heart J. 2004;25:1003-8.

8. Zammaretti P, Zisch AH. Adult "endothelial progenitor cells". Renewing vasculature Int J Biochem Cell Biol. 2005;37:493-503.

9. Fadini GP, Tognon S, Rodriguez L, Boscaro E, Baesso I, Avogaro A, et al. Low levels of endothelial progenitor cells correlate with disease duration and activity in patients with Behçet's disease. Clin Exp Rheumatol. 2009;27:814-21.

10. Hristov M, Erl W, Weber PC. Endothelial progenitor cells: mobilization, differentiation, and homing. Arterioscler Thromb Vasc Biol. 2003;23:1185-9.

11. Asahara $\mathrm{T}$, Takahashi $\mathrm{T}$, Masuda $\mathrm{H}$, Kalka $\mathrm{C}$, Chen D, Iwaguro $\mathrm{H}$, et al. VEGF contributes to postnatal neovascularization by mobilizing bone marrow-derived endothelial progenitor cells. EMBO J. 1999;18:3964-72.

12. Aicher A, Zeiher AM, Dimmeler S.. Mobilizing endothelial progenitor cells Hypertension. 2005;45:321-5.

13. Bozkirli ED, Keşkek SÖ, Kozanoğlu I, Yücel AE. High levels of endothelial progenitor 
cells can be associated with thrombosis in patients with Behçet's disease. Clin Exp Rheumatol. 2014;32( Suppl 84):S49-53.

14. Kutlay S, Calayoglu R, Boyvat A, Turkcapar N, Sengul S, Keven K, et al. Circulating endothelial cells: a disease activity marker in Behçet's vasculitis? Rheumatol Int. 2008:29:159-62.

15. Criteria for diagnosis of Behçet's disease. International Study Group for Behçet's Disease. Lancet. 1990;335:1078-80.

16. George J, Goldstein E, Abashidze S, Deutsch V, Shmilovich H, Finkelstein A, et al. Circulating endothelial progenitor cells in patients with unstable angina: association with systemic inflammation. Eur Heart J. 2004;25:1003-8.

17. Heeschen C, Lehmann R, Honold J, Assmus B, Aicher A, Walter DH, et al. Profoundly reduced neovascularization capacity of bone marrow mononuclear cells derived from patients with chronic ischemic heart disease. Circulation. 2004;109:1615-22

18. Keşkek ŞÖ, Bozkırlı-Ersözlü ED, Kozanoglu I, Yücel AE. High Levels of Circulating Endothelial Progenitor Cells Are Associated with Acrotism in Patients with Takayasu Arteritis. Med Princ Pract. 2017;26:132-8.

19. Deng XL, Li XX, Liu XY, Sun L, Liu R. Comparative study on circulating endothelia progenitor cells in systemic lupus erythematosus patients at active stage. Rheumatol Int. 2010;30:1429-36.

20. Westerweel PE, Luijten RK, Hoefer IE, Koomans HA, Derksen RH, Verhaar MC. Haematopoietic and endothelial progenitor cells are deficient in quiescent systemic lupus erythematosus. Ann Rheum Dis. 2007;66:865-70.

21. Grisar J, Aletaha D, Steiner CW, Kapral T, Steiner S, Seidinger D, et al. Depletion of endothelial progenitor cells in the peripheral blood of patients with rheumatoid arthritis. Circulation. 2005;111:204-11

22. Herbrig K, Haensel S, Oelschlaegel U, Pistrosch F, Foerster S, Passauer J. Endothelial dysfunction in patients with rheumatoid arthritis is associated with a reduced number and impaired function of endothelial progenitor cells. Ann Rheum Dis. 2006;65:157-63.

23. Jodon de Villeroché V, Avouac J, Ponceau A, Ruiz B, Kahan A, Boileau C, et al. Enhanced late-outgrowth circulating endothelial progenitor cell levels in rheumatoid arthritis and correlation with disease activity. Arthritis Res Ther. 2010;12:R27.

24. Robak E, Kierstan M, Cebula B, Krawczynska A, Sysa-Jedrzejowska A, Wierzbowska $A$, et al. Circulating endothelial cells and angiogenic proteins in patients with systemic lupus erythematosus. Lupus. 2009;18:332-41.

25. Grisar J, Steiner CW, Bonelli M, Karonitsch T, Schwarzinger I, Weigel G, et al. Systemic lupus erythematosus patients exhibit functional deficiencies of endothelial progenitor cells. Rheumatology (Oxford). 2008;47:1476-83.

26. Camoin-Jau L, Kone-Paut I, Chabrol B, Sampol J, Dignat-George F. Circulating endothelial cells in Behçet's disease with cerebral thrombophlebitis. Thromb Haemost. 2000;83:631-2.

27. Orem A, Arıca DA, Mentese A, Yaman SO, Ural ZK, Bahadır S. Platelet-endothelial molecule SCUBE1 levels in patients with Behcet's disease: A preliminary study. Clin Chim Acta. 2017:473:157-9.

28. Örem A, Yayli S, Arıca DA, Akcan B, Yücesan FB, Bahadir S. Lipoproteinassociated phospholipase A2 level in patients with Behçet's disease. J Eur Acad Dermatol Venereol. 2013;27:e289-93.

29. Orem A, Yandi YE, Vanizor B, Cimșit G, Uydu HA, Malkoç M.. The evaluation of autoantibodies against oxidatively modified low-density lipoprotein (LDL), susceptibility of LDL to oxidation, serum lipids and lipid hydroperoxide levels, total antioxidantstatus, antioxidant enzyme activities, and endothelial dysfunction in patients with Behçet's disease. Clin Biochem. 2002;35:217-24

30. Harada M, Mitsuyama K, Yoshida H, Sakisaka S, Taniguchi E, Kawaguchi T, et al. Vascular endothelial growth factor in patients with rheumatoid arthritis. Scand J Rheumatol. 1998:27:377-80.

31. Soubrier M, Dubost JJ, Serre AF, Ristori JM, Sauvezie B, Cathebras P, et al. Growth factors in POEMS syndrome: evidence for a marked increase in circulating vascular endothelial growth factor. Arthritis Rheum. 1997;40:786-7.

32. Terai M, Yasukawa K, Narumoto S, Tateno S, Oana S, Kohno Y. Vascular endothelia growth factor in acute Kawasaki disease. Am J Cardiol. 1999;83:337-9.

33. Cekmen M, Evereklioglu C, Er H, Inalöz HS, Doganay S, Türköz Y, et al. Vascular endothelial growth factor levels are increased and associated with disease activity in patients with Behçet's syndrome. Int J Dermatol. 2003;42:870-5.

34. Erdem F, Gündoğdu M, Kiki I, Ali Sari R, Kiziltunç A. Vascular endothelial and basic fibroblast growth factor serum levels in patients with Behçet's disease. Rheumatol Int. 2005;25:599-603.

35. Yalçındağ A, Gedik-Oğuz Y, Yalçındağ FN. The relationship between serum levels of angiogenin, bFGF, VEGF, and ocular involvement in patients with Behçet's disease. Graefes Arch Clin Exp Ophthalmol. 2013;251:1807-12.

36. Kamoun M, Houman MH, Hamzaoui A, Hamzaoui K. Vascular endothelia growth factor gene polymorphisms and serum levels in Behçet's disease. Tissue Antigens. 2008;72:581-7.

37. Oztürk MA, Unverdi S, Oktar S0, Bukan N, Gülbahar 0, Ureten K, et al. Vascular endothelial growth factor and carotid intima-media thickness in patients with Behçet's disease. Clin Rheumatol. 2008:27:961-6.

38. Katsuda S, Okada Y, Okada Y, Imai K, Nakanishi I. Matrix metalloproteinase-9 (92kd gelatinase/type IV collagenase equals gelatinase B) can degrade arterial elastin. Am J Pathol. 1994;145:1208-18.

39. Pay S, Abbasov T, Erdem H, Musabak U, Simsek I, Pekel A, et al. Serum MMP2 and MMP-9 in patients with Behçet's disease: do their higher levels correlate to vasculo-Behçet's disease associated with aneurysm formation? Clin Exp Rheumatol. 2007;25(Suppl 45):S70-5.

40. Takeshita S, Tokutomi T, Kawase H, Nakatani K, Tsujimoto H, Kawamura Y, et al. Elevated serum levels of matrix metalloproteinase-9 (MMP-9) in Kawasaki disease. Clin Exp Immunol. 2001;125:340-4

41. Sorbi D, French DL, Nuovo GJ, Kew RR, Arbeit LA, Gruber BL. Elevated levels of 92-kd type IV collagenase (matrix metalloproteinase 9) in giant cell arteritis. Arthritis Rheum. 1996:39:1747-53.

42. Matsuyama A, Sakai N, Ishigami M, Hiraoka H, Kashine S, Hirata A, et al. Matrix metalloproteinases as novel disease markers in Takayasu arteritis. Circulation. 2003;108:1469-73.

43. Aksoy Y, Ercan A, Dalmizrak 0, Canpinar H, Kartal Durmazlar SP, Bayazit M, et al. The determination of matrix metalloproteinase 9 activity and gene expression levels in Behcet's disease patients with aneurysmal complications. Clin Rheumatol. 2011:30:515-9.

44. Naouali A, Kaabachi W, Tizaoui K, Amor AB, Hamzaoui A, Hamzaoui K. Association of MMP-9 gene polymorphisms with Behçet's disease risk. Immunol Lett. 2015;164:18-24.

45. Lee YJ, Kang SW, Baek HJ, Choi HJ, Bae YD, Kang EH, et al. Association between matrix metalloproteinase 9 promoter polymorphisms and Behçet's disease. Hum Immunol. 2010;71:717-22.

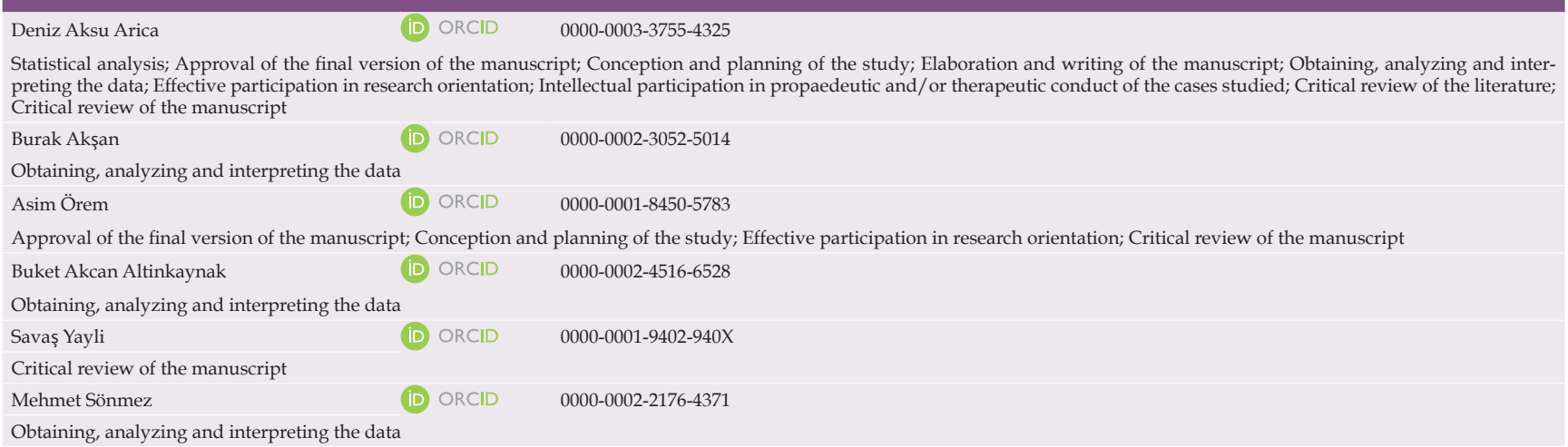

How to cite this article: Arica DA, Aksan B, Orem A, Altinkaynak BA, Yayli S, Sonmez M. High levels of endothelial progenitor cells and circulating endothelial cells in patients with Behçet's disease and their relationship to disease activity. An Bras Dermatol. 2019;94(3):320-6. 